\title{
Investigation of Blood Hormone and Respiratory Parameters in Active and Passive Tolerance Period after Anaerobic Test in Football Players
}

\author{
Betül Akyol ${ }^{1}$, Serdar Şerare ${ }^{2}$ \\ ${ }^{1}$ Inonu University, Faculty of Sport Sciences, Turkey \\ ${ }^{2}$ Inonu University, Institute of Health Sciences, Turkey \\ Correspondence: Betül Akyol, Inonu University, Faculty of Sport Sciences, Turkey.
}

Received: July 17, 2018

doi:10.11114/jets.v6i9a.3551
Online Published: August 17, 2018

URL: https://doi.org/10.11114/jets.v6i9a.3551

\begin{abstract}
The aim of the study was to determine the changes in blood hormone and respiratory parameters in recovery phases. 28 voluntary men participated in the study, with an average age of $19.75 \pm 1.61$ years and playing active football during the league season. Wingate Anaerobic Power Test and Respiratory Function Test (RFT) were applied to the subjects who were randomly divided into two groups, active and passive group. Blood samples were collected from and RFT was applied to all subjects before and after the test. Cortisol hormone, Partial Oxygen Pressure (PO2), Partial Carbon Dioxide Pressure (PCO2), lactic acid (LA) values were obtanied with datas taken from blood samples. The forced vital capacity (FVC), forced expiratory volume (FEV1), and rate of 1 . Second of forced expiratory volume to the forced vital capacity (FEV1 / FVC) were measured by the PFT test. SPSS 24.0 program was used for statistical evaluation of the data. As a result; both 5-minute active and passive recovery methods did not reduce the cortisol ratio, but continued to increase in minute increments. In terms of $\mathrm{PO}_{2}$, passive recovery was found to be a more effective method than active recovery. 5 minutes of active and passive recovery did not reduce LA level and did not affect each other significantly. $\mathrm{FVC}$ and $\mathrm{FEV}_{1}$ values were found to be higher in the active recovery group than in the passive recovery group at the onset of AT recovery. Active recovery was found to have positive effects on vital capacity FVC and FEV ${ }_{1}$.
\end{abstract}

Keywords: wingate anaerobic power test, respiratory function test, active and passive recovery, cortisol hormone, lactic acid

\section{Introduction}

Nowadays aerobic capacity for healthy life and anaerobic capacity for performance sports becomes a necessity. Often there is a need for anaerobic performance in counterattack and suppressed defenses of team competitions like football, in the last minute sprints of athletics, and more sports (Çakmakçı, 2013). The energy changes, the fundamental condition of muscle contraction to bring about anaerobic performance, and the compounds that emerge as ready energy as a result of reduction of energy change are very important for muscles and for exercise (Sevim, 2010). Nowadays, the intensity of exercise and how much energy will be consumed can be predicted to a great extent and the performance appraisal is based on how long energy resources and connected systems can be renewed. The first energy source of the exercise is Adenosine Triphosphate (ATP). After that, the other three energy systems take over the task, respectively, according to the intensity and duration of the activity (Günay, Cicioğlu \& Kara, 2006). One of these systems is the lactic acid system or anaerobic glycolysis. "The anaerobic glycolysis term is used for types of exercise self-produced necessary energy for cell without oxygen $\left(\mathrm{O}_{2}\right)$ " (Karakuşoğlu, 2008). Glucose and glycogen in the anaerobic glycolysis environment dissociate to LA without the need for $\mathrm{O}_{2}$. So that averaging $4 \mathrm{millimol} / \mathrm{liter}(\mathrm{mmol} / \mathrm{lt})$ of ATP synthesis is provided and two of them are used as movement energy (Noyan, 1996). It is observed LA conversion as there is no O2 in the environment while glycogen divided by decomposition. When intertitial fluid and LA reaching the blood starts to accumulate and reaches high density (Bompa, 2011), it lowers the acid base balance (pH) of the body and makes muscle contraction difficult, resulting in fatigue and even termination of exercise (Çakmakçı et al., 2010). Cortisol hormone is also effective in exercise. The organism perceives exercise as a stress factor and increases some hormone levels such as glucagon in blood, cortisol and growth hormone (Pınar, 2015). Depending on the severity of exercise, cortisol blocks protein synthesis and increases protein catabolism in order to provide an energy source at the stage when energy is beginning to become insufficient. It also makes the concentration of amino acids with fatty acids of lipids in liver 
tissues and provides energy to the muscles by enabling the gluconeogenesis to occur (Hazar et al., 2011). Respiration parameters also work intensively during exercise and recovery. The levels of respiratory parameters can be measured by tests with linear (test that the metabolism increases from stable to the end of the current level) increasing resistance versus constant resistance with aerobic and anaerobic activity (Temoçin et al., 2004). The air taken in breathing is inspiration, the air expelled is expiration. The amount of air blown out at maximum level of expiration in the continuation of maximum inspiration is a demanding vital capacity and an important parameter (Atabek, 2015). The most important functions of respiration are; gas exchange; the removal of $\mathrm{O}_{2}$ and the introduction of carbon dioxide $\left(\mathrm{CO}_{2}\right)$, the body heat level and water, the loss of heat. $\mathrm{O}_{2}$ requirement changes is dependent on the intensity and duration of muscle contraction in the unit. The $\mathrm{O}_{2}$ diffusion capacity significantly affects the $\mathrm{O}_{2}$ capacity in the exercise while demonstrating the rate of $\mathrm{O}_{2}$ passing from the alveoli to the blood (Çakmakçı, Fişekçioğlu, Çınar, Akkuş \& Kılıç, 2005). The amount of $\mathrm{O}_{2}$ and $\mathrm{CO}_{2}$ gases entering and exiting the tissues in the molten state is determined by the partial pressure of the gas and the degree of dissolution (Ackerman, 2006). Normally, while the hemoglobin $(\mathrm{Hb}) \mathrm{O}_{2}$ saturation is $98 \%$ in $\mathrm{PO}_{2}$ of 100 millimeters ( $\mathrm{mmHg}$ ) (Gelir et al., 2013). The $\mathrm{O}_{2}$ saturation of the venous blood is about 70-75\% (Koçoğlu, 2006). In a high-intensity exercise, $\mathrm{O}_{2}$ consumption and $\mathrm{CO}_{2}$ emissions may increase 20 times. Cells start to use more $\mathrm{O}_{2}$ for metabolism, in which case the amount of interstitial fluid $\mathrm{PO}_{2}$ decreases, $\mathrm{PCO}_{2}$ increase (Kaya, 1994), LA level in the blood increases by consisting metabolic acidosis, and decreases $\mathrm{pH}$. When the intensity of the exercise drops or the recovery starts, as the blood flow increases, after a while the $\mathrm{O}_{2}$ reaching the tissues increases and the $\mathrm{PO}_{2}$ increases (Çakmakç1 et al., 2010). At the level of bicarbonate $\left(\mathrm{HCO}_{3}\right)$ transported in the plasma, an increase is observed in the time of 5 to 30 minutes in the zone where fatigue occurs, but LA responds to the real level within 1-2 hours of time. PH balance is stabilized when the bicarbonate reaches the values required for the buffering task (Kaya,1994). Immediately after the activity, the energy expenditure of the metabolism continues in a linear manner, the activities in the organism continues for a while and does not immediately fall to the resting level, and the use of $\mathrm{O}_{2}$ continues during the rest period. It is aimed to recover muscles to resting level before exercise by recovering after exercise. The sportsman can recover quickly after exercise based on the reimbursement of the $\mathrm{O}_{2}$ borrow in the exercise, the renewal of energy source repositories, the removal of LA from blood and muscle, and the renewal of the $\mathrm{O}_{2}$ myoglobin stores (Günay, Cicioğlu \& Kara, 2006). Athletes who can be recovered quickly and in a shorter time may perform at a higher level against their competitors (Demiriz, Erdemir \& Kayhan, 2015).

The aim of this study was to investigate the changes of cortisol hormone, blood gases, LA and respiratory capacity parameters and their affects upon each other after the anaerobic test on phsical education students' active playing football during 5 minutes of active and passive recovery phases.

\section{Methods}

The study that is approved by Inonu University Clinical Research Ethics with protocol of 2016/170, was made in Sivas Cumhuriyet University Physiotherapy and Cardiopulmonary Rehabilitation Unit. The study was conducted on 28 voluntary male football players who were actively playing football, 19.75 \pm 1.61 years of age, physical education and sport student. The subjects were informed by an informed consent form and required permission was obtained from the relevant university. Blood samples were collected from all subjects before the test (BT), after the test (AT), at the third minute of the recovery period (3MRP) and at the fifth minute of the recovery period (5MRP). The Respiratory Function Test was applied to all subjects before, after, and at the fifth minute of recovery.Weight measurements of subjects Felix Magro on 100 gr. precision scale, and height measurements were measured on $1 \mathrm{~mm}$ precision $\mathrm{F}$. BOSCH Medizintechnik brand metal height gauge fixed to the wall. Resting heart rate of subjects was measured by telemetric heart rate monitor (Polar 610i, Finland) and 40\% was calculated.

\subsection{Wingate Anaerobik Power Test (WanT)}

WanT test a modified Monark $824 \mathrm{E}$ model (made in Sweden) with a modified bifold for WanT was made on the foot bicycle ergometer. For the test, a load of $75 \mathrm{~g} / \mathrm{kg}$ was calculated for each $\mathrm{kg}$ of body weight of all subjects. Pre-WanT subjects were rested for 5 minutes on the cycling ergometer by warming them with small sprints, then resting for 2 minutes without resistance or sitting on an ergometer just to stabilize fatigue, muscle heat and blood flow during warming. They wanted to reach the highest pedal cycle in the shortest time period without resistance in the acceleration phase. The test was started at a range of 2 to 5 seconds when the weight of the ergometer was estimated to be $75 \mathrm{~g} / \mathrm{kg}$ body weight. The subjects pedaled in the supramaximal pedal cycle in resistance time of 30 seconds. Subjects were orally supported during the test.

\subsection{Respiratory Function Test (SFT)}

Care Fusion Run-7402 brand Ergo spirometer was used to measure respiratory functions. Spirometer measurements were taken as the best values as the result of triple breathing of the subjects after compression of their nose with clamps and maximum breathing. Volume (L) was used as the unit of measure. 


\subsection{Active and Passive Recovery}

Active recovery group after WanT was actively recovered at $40 \pm 10 \%$ heart rate interval followed by Covidien's Nellcor SpO2 monitor system connection from the Proitness 3000-3AC treadmill. The passive recovery group recovered passively only by sitting.

\subsection{Blood and Hormone Measurement}

The study was conducted early in the day and the subjects were hungry for better measuring of hormone levels and better outcome. Venous blood samples were collected from all subjects four times in total including CT, AT, RP3M and RP5M. The blood taken for cortisol hormone level was centrifuged at $3500 \mathrm{rev}$ and plasma and sera were separated. Hitachi Cobas 6000 device for cortisol hormone, ABL 800 devices for blood gases and LA level were used. Increased blood was taken to the hospital cold tube store at $-80 \mathrm{C}^{\circ}$ in ependorf tubes. It was used in units of micrograms/deciliter (mcg/dl) for cortisol hormone, millimeter $(\mathrm{mmHg})$ for $\mathrm{PO} 2$ and $\mathrm{PCO}$, and milimol/liter (mmol/l) for lactic acid.

\section{Results}

The data were given in median (min-max). The normal distribution relevance of the data was examined by the Shapiro Wilk test. Mann-Whitney U test was used to examine differences between groups. Significance level was determined as $\mathrm{p}<0.05$ and theanalyzes were done in IBM SPSS statistic 24.0 program.

Table 1. Descriptive statistics of age, height, weight, BMI variables

\begin{tabular}{|c|c|c|c|c|}
\hline \multirow{3}{*}{ Variables } & \multicolumn{4}{|l|}{ Groups } \\
\hline & Active $(n=14)$ & & Passive $(n=14$ & \\
\hline & Avarage \pm SD & Median (Min-Maks) & Avarage \pm SS & Median (Min- Maks) \\
\hline & $19.43 \pm 1.16$ & $19.00(17.00-21.00)$ & $20.07 \pm 2.06$ & $20.50(17.00-24.00)$ \\
\hline & +5.59 & $.00-190.00)$ & \pm 7.71 & $66.00-194.00)$ \\
\hline Weight & $72.96 \pm 7.76$ & $73.50(56.70-83.30)$ & $73.52 \pm 9.13$ & $74.10(55.60-90.80)$ \\
\hline BMI & $23.35 \pm 2.41$ & $23.35(19.90-28.20)$ & $22.51 \pm 2.21$ & $22.30(19.20-28.70)$ \\
\hline
\end{tabular}

SS: Standard deviation

The mean age of the participating active group was $19.43 \pm 1.16$, the passive group was $20.07 \pm 2.06$, the mean height of the participating active group was $176.71 \pm 5.59$, the passive group was $180.64 \pm 7.71$, the mean weight of the participating active group was $72.96 \pm 7.76$, the passive group was $73.52 \pm 9.13$, the mean Body Mass Index of the participating active group was $23.35 \pm 2.41$, and the passive group was $22.51 \pm 2.21$.

Table 2. Comparison of CT, AT, RP3M and RP5M cortisol hormone levels of active and passive recovery groups.

\begin{tabular}{llll}
\hline Variables & $\begin{array}{l}\text { Active } \\
(\mathbf{n = 1 4})\end{array}$ & $\begin{array}{l}\text { Passive } \\
(\mathbf{n = 1 4})\end{array}$ & $\mathbf{p}$ \\
\hline BT_kor (Median \pm SD) & $10.91 \pm 4.22$ & $12.44 \pm 4.26$ & 0.35 \\
AT_kor (Median \pm SD) & $11.43 \pm 5.12$ & $11.62 \pm 4.16$ & 0.916 \\
RP3M_kor (Median \pm SD) & $11.02 \pm 5.17$ & $10.83 \pm 4.01$ & 0.913 \\
RP5M_kor (Median \pm SD) & $11.30 \pm 5.06$ & $11.04 \pm 4.10$ & 0.882 \\
\hline
\end{tabular}

In Table 2, There was no statistically significant difference between active and passive groups in terms of cortisol measurements at different times $(\mathrm{p}<0.05)$.

Table 3. Comparison of active and passive recovery BT, AT, RP3M and $\mathrm{RP} 5 \mathrm{~m} \mathrm{pO}_{2}$ levels

\begin{tabular}{|c|c|c|c|}
\hline Variables & $\begin{array}{l}\text { Active } \\
(n=14)\end{array}$ & $\begin{array}{l}\begin{array}{l}\text { Passive } \\
(n=14)\end{array} \\
\text { (n) }\end{array}$ & $\mathbf{p}$ \\
\hline BT_pO 2 (Median (Min-maks)) & $36.55(28.8-67.1)$ & $40.7(29.2-58.6)$ & 0.52 \\
\hline $\mathrm{AT}_{-} \mathrm{pO}_{2}($ Median (Min-maks)) & $33.9(26.2-83.3)$ & $37.9(27.2-90.3)$ & 0.613 \\
\hline RP3M_pO ${ }_{2}($ Median (Min-maks)) & $44.85(28.7-95.2)$ & $62(34.7-124)$ & 0.031 \\
\hline $\mathrm{RP} 5 \mathrm{M} \_\mathrm{pO} \mathrm{O}_{2}($ Avarage $\pm \mathrm{SD})$ & $52.29 \pm 15.36$ & $73.38 \pm 23.47$ & 0.009 \\
\hline
\end{tabular}

In the Table 3, there was a statistically significant difference between the active and passive groups in terms of $\mathrm{pO}_{2}$ measurements performed in the third and fifth minutes, while there was no statistically significant difference between active and passive groups in terms of $\mathrm{pO}_{2}$ measurements at other times $(\mathrm{p}<0.05)$.

Table 4. Comparison of BT, AT, RP3M and $\mathrm{RP} 5 \mathrm{M} \mathrm{pCO}_{2}$ levels of active and passive recovery groups

\begin{tabular}{|c|c|c|c|}
\hline Variables & $\begin{array}{l}\text { Active } \\
(n=14)\end{array}$ & $\begin{array}{l}\text { Passive } \\
(n=14)\end{array}$ & $\mathbf{p}$ \\
\hline Median \pm SD) & $45.89 \pm 5.36$ & $45.66 \pm 5.96$ & 0.916 \\
\hline AT_PCO 2 (Median \pm SD) & $53.76 \pm 10.54$ & $51.69 \pm 8.57$ & 0.573 \\
\hline $\mathrm{RP} 3 \mathrm{M} \quad \mathrm{PCO}_{2}(\mathrm{Median} \pm \mathrm{SD})$ & $45.37 \pm 8.01$ & $40.56 \pm 7.53$ & 0.114 \\
\hline RP5M_PCO 2 (Avarage (Min-maks)) & $40.7(32.8-53.9)$ & $35.35(31.3-51.4)$ & 0.041 \\
\hline
\end{tabular}

In the Table 4, there was a statistically significant difference between the active and passive groups in terms of PCO2 
measurement at the 5th minute, while there was no statistically significant difference between active and passive groups in terms of $\mathrm{PCO} 2$ measurements at other times $(\mathrm{p}<0.05)$.

Table 5. Comparisons of TÖ, TS, TP3D and TP5D LA levels of active and passive recovery groups

\begin{tabular}{llll}
\hline Variables & $\begin{array}{l}\text { Active } \\
(\mathbf{n = 1 4})\end{array}$ & $\begin{array}{l}\text { Passive } \\
(\mathbf{n = 1 4})\end{array}$ & $\mathbf{p}$ \\
\hline BT_lac (Avarage \pm SD) & $1.31 \pm 0.34$ & $1.84 \pm 0.42$ & $\mathbf{0 . 0 0 1}$ \\
AT_lac (Avarage \pm SD) & $8.17 \pm 1.87$ & $8.85 \pm 2.86$ & 0.462 \\
RP3M_lac (Avarage \pm SD) & $10.11 \pm 3.14$ & $10.55 \pm 3.25$ & 0.719 \\
RP5M_lac (Avarage \pm SD) & $9.11 \pm 2.87$ & $10.50 \pm 3.61$ & 0.268 \\
\hline
\end{tabular}

In the table 5,there was a statistically significant difference between the active and passive groups in terms of lactic acid measurement before the test, while there was no statistically significant difference between active and passive groups in terms of lactic acid measurements at other times $(\mathrm{p}<0.05)$.

Table 6. Comparison of BT, AT, and RP5m FEV1 levels of active and passive recovery groups

\begin{tabular}{llll}
\hline Variables & $\begin{array}{l}\text { Active } \\
(\mathbf{n = 1 4})\end{array}$ & $\begin{array}{l}\text { Passive } \\
(\mathbf{n = 1 4})\end{array}$ & $\mathbf{p}$ \\
\hline BT_FEV1 (Avarage \pm SD) & $106.64 \pm 26.62$ & $95.71 \pm 17.73$ & 0.212 \\
AT_FEV1 (Avarage \pm SD) & $118.21 \pm 18.64$ & $98.57 \pm 18.94$ & $\mathbf{0 . 0 1}$ \\
RP5M_FEV1 (Avarage \pm SD) & $114.93 \pm 20.98$ & $102.57 \pm 16.57$ & 0.095 \\
\hline
\end{tabular}

In Table 6, there was a statistically significant difference between the active and passive groups in terms of FEV1 after the test, while there was no statistically significant difference between the active and passive groups in terms of FEV1 measurements at other times $(\mathrm{p}<0.05)$.

Table 7. Comparison of BT, AT, and RP5M FVC levels of active and passive recovery groups

\begin{tabular}{llll}
\hline Variables & $\begin{array}{l}\text { Active } \\
(\mathbf{n = 1 4})\end{array}$ & $\begin{array}{l}\text { Passive } \\
(\mathbf{n = 1 4})\end{array}$ & $\mathbf{p}$ \\
\hline BT FVC (Avarage \pm SD) & $116.36 \pm 14.34$ & $102.07 \pm 11.61$ & $\mathbf{0 . 0 0 8}$ \\
AT FVC (Ortanca (Min-maks)) & $105(94-141)$ & $100(81-127)$ & $\mathbf{0 . 0 4 3}$ \\
RP5M FVC (Ortanca (Min-maks)) & $108(96-145)$ & $102.50(82-123)$ & 0.0888 \\
\hline
\end{tabular}

In Table 7, there was no statistically significant difference between the active and passive groups in terms of FVC measurement at 5 minutes, while there was a statistically significant difference between active and passive groups in terms of FVC measurements at other times ( $\mathrm{p}<0.05)$.

Table 8. Comprasion of Active and passive recovery BT, AT, and RP5M FEV1 / FVC levels

\begin{tabular}{llll}
\hline Variables & $\begin{array}{l}\text { Active } \\
(\mathbf{n = 1 4})\end{array}$ & $\begin{array}{l}\text { Passive } \\
(\mathbf{n = 1 4})\end{array}$ & $\mathbf{p}$ \\
\hline BT FEV1/FVC (Median (Min-maks)) & $81.34(59.26-90.51)$ & $80.32(53.16-90.54)$ & 0.854 \\
AT FEV1/FVC (Avarage \pm SD) & $88.423 \pm 6.81$ & $80.99 \pm 12.41$ & 0.063 \\
RP5M FEV1/FVC (Avarage \pm SD) & $83.53 \pm 7.70$ & $82.63 \pm 10.27$ & 0.796 \\
\hline
\end{tabular}

In Table 7, here is no statistically significant difference between the active and passive groups in terms of FEV1 / FVC measurements performed at different times $(\mathrm{p}<0.05)$.

\section{Discussion}

There was no significant difference between the two groups in the levels of cortisol hormone levels of TCE, TS, TP3D and TP5D in the study of active and passive recovery after WanT test $(\mathrm{p}<0.005)$. The level of cortisol hormone before anaerobic test was higher in both groups due to strase. RP3M and RP5M did not show a significant decrease in both active and passive groups. As a matter of fact, Albayrak et al. (2013) reported that there was no significant change in cortisol hormone levels before and after submaximal training in their study of 10 footballers with a mean age of 17 . Wahl et al. (2013) reported that active and passive recovery methods affect LA and PH, but to date, there have been few studies examining the effects of acute hormonal response on parameters in active and passive recovery and the study did not find a significant difference in active and passive recovery cortisol rate in the study. When there is a certain target, they have associated exacerbated metabolic stress with acute hormonal responses that are in a healing mode Özmerdivenli \& Karacabey (2000) have applied aerobic and anaerobic exercises by separating the students of 60 (30 male, 30 female) Physical education department into 3 separate groups and they reported that cortisol levels decreased after 4 hours from exercise, affected by many factors related to the stress and varied depending on exercise type. Ersöz et al. (1996) applied passive recovery 9 athletic athletes with a mean age of 23after submaximal exercise for 45 minutes at $60-70 \%$ VO2max workload. They have arrived that 45 minutes of activity at the 60-70\% intensity of the plasma cortisol reaction did not change at the time of activity (45 minutes), reached peak at 30 minutes of post-activity recovery, maintained peak value even at 60 minutes, and decreased to resting level after 120 minutes. Hoffman \& Pedersen (1994) reported that plasma cortisol ratios started to increase at set time-span intensive activities and that maximal 
concentrations would reach 20 minutes after exercise and that the cortisol ratio in both aerobic and anaerobic activities would be high 90 minutes. In our study, there was no significant change between AT cortisol level and RP3M and RP5M cortisol levelsWhen the literature review, it has been reported that there is a linear increase in cortisol hormone level after aerobic exercise over a certain percentage. In our study, the lack of a decrease in TP5D cortisol level during the subsequent active and passive recovery processes of anaerobic exercise indicates that there is no short-term effect of active and passive recovery and shows that the increase in cortisol concentration may continue in the following minutes of recovery. In our study, venous blood values were examined and $\mathrm{PO}_{2}$ value recovery after WanT was higher than RP3M and RP5M passive recovery group ( $<<0.005)$. We found that the $\mathrm{PO}_{2}$ effect is better in the active recovery group than in the passive recovery group. As a matter of fact, $\mathrm{PCO}_{2}$ value was found lower in TP5D passive recovery. No significant difference was found at other times $(\mathrm{p}<0.005)$. We think that the reason for this is that after the test the active recovery group continues to exhaust and the passive recovery group is the rest. It is known that a high-intensity activity forms hypoxia in arterial blood. In the result of passive recovery reduces the heart rate to the relaxation rate at rest, arterial blood will receive more $\mathrm{O} 2$. For this reason, $\mathrm{PO} 2$ was found to be higher in passive recovery. Koyama et al. (2000) in the study of 21 volunteers with coronary disease applied active and passive recovery after cyclical ergometry with a symptom-free incremental maximal exercise test. According to active recovery, passive recovery has beneficial effects on the respiratory system. Wahl et al. (2013) have applied WanT to 12 triatlet cyclists as our work. When they compared the $\mathrm{PO} 2$ values in active and passive recovery, they found that $\mathrm{PO} 2$ was significantly higher in the passive recovery direction as the result we obtained. Fashi et al. (2014) applied a high intensity endurance test (RHIET), which lasted for 2 minutes 30 seconds and last 30 seconds with maximum power, to 10 physical education department students. As a result of active stretching and passive recovery after exercise, they compared arterial blood samples rather than venous blood, which is the limit of our study. Passive recovery strongly suggests that the $\mathrm{O} 2$ arterial pressure is greater than the active and tension healing and this strongly supports the outcome of our work. They also assumed that the energy required for short-term active recovery would result in less oxygen because of to release LA concentrations, to resynthesize phosphocreatine and to refill myoglobin and haemoglobin. Thomas et al. (2014) have given drinks with carbohydrate, bicarbonate and placebo to 12 athletes during rest, and then applied three different of active and passive recovery after three different sprint tests. As a result, they compared the blood samples of passive recovery with other recovery methods and found no significant difference in terms of $\mathrm{PO}_{2}$. Dupontg \& Berthoin, 2004) have compared the effects of post-training recovery types on the 12 male subjects. As a result, they reported that $\mathrm{PO}_{2}$ was significant for passive recovery when compared to active recovery, when tired during repeated high intensity exercise. In our study and supporting studies in the literature, passive recovery after an anaerobic exercise was found to be a more effective method in terms of $\mathrm{PO}_{2}$. There was no significant difference between BT, AT, RP3M, RP5M blood LA in levels of active recovery and passive recovery groups after WanT $(\mathrm{p}<0.05)$. It has increased considerably during and after exercise compared to the level of rest. This increase in RP3M did not even reach the level of rest at RP5M. Although many studies have been reported that active recovery is more effective, many studies have reported no significant difference. Although there was a difference between active recovery and passive recovery in this study, no significant difference was found. While (Bosak, Bishop, Smith, Green, Richardson \& Iosia, 2006) in their study for 12 athletic athletes did not find a meaningful difference in between the two methods of recovery in terms of LA, They found that there was a difference between the recovery times in some sportsmen. Therefore, they stated that the recovery should be applied according to the person. (Harbili et al. (2007) in a study for 22 male athletes have applied active recovery to half of them, passive recovery to the other half after WanT. Although 10 minutes of active recovery was at blood LA level and 10 minutes of passive recovery was lower than blood LA level, no significant difference was found. Again Gürses et al. (2016) in their study for 5 male and 5 female athletes from National Swimming Team in 3 different days have applied 3 different recovery methods after anaerobic test and they did not find statistically significant difference between groups in terms of LA. Sarı et al. (2016) have applied practiced active relaxation by walking and relaxation with massage methods to 15 male athletes after swimming training they had done on different days. There was no statistically significant difference in terms of LA. Hazır \& Gül (2015) have applied to the 11 active athletes for every other day and 3 times after the WanT 20 minutes sitting passive recovery, core exercise combined with passive recovery and active recovery in the cycling ergometry. They did not find any statistically significant difference in the LA exluding rate. Bonen and Belcastro have used a range of recovery strengths ranging from $30 \%$ to $80 \% \mathrm{VO} 2 \mathrm{max}$ in one study and found that as the intensity increased, the amount of lost LA decreased. Active recovery; Heart, liver and kidneys can be work easier in the muscles accumulated lactic acid (Alemdaroğlu \& Koz, 2011). However, studies that argue that the method of active recovery is effective in recovering is a matter of debate about the duration of active recovery; In these studies, it has been reported that active listening, which takes 3-5 minutes positively affects performance, but this result is independent from LA. While the impact of active recovery on reducing LA acid levels has been confirmed in many studies, there are also contradictions concernd with performance outcomes (Arslan et al., 2006). In our study, the same result could not be obtained with the literature because of the measurement with venous 
blood. However, the presence of a number of studies supporting the outcome of our study suggests that active and passive recovery methods are not clearly demonstrated to be more effective. When observations in the respiratory phase are evaluated, two or more parameters of lung volume capacities should be evaluated together (Çakmakçı et al., 2005). In our study, the respiratory parameters that we found to be meaningful were forced vital capacity (FVC) while the other was the maximal respiratory gas volume $\left(\mathrm{FEV}_{1}\right)$ (Atan et al., 2013). In literature, studies in this area are usually limited to pre-exercise and immediate after measures. There is no so many studies to investigate the reactions of FVC and FEV1 in post-exercise recovery phases, so the examination of FVC and FEV1 values in our study recovery phase is originally based on primary studies in this area. $\mathrm{FVC} / \mathrm{FEV}_{1}$ measurements $\mathrm{in}$ the respiration function test performed before WanT, WanT and RP5M showed no statistically significant difference in terms of active and passive recovery, while FVC was found to be lower in the passive recovery group than in the active recovery group. RP5M values returned to values at rest level. We think that active recovery affects vital capacity positively. FEV $_{1}$ value was found to be lower in passive recovery group than active recovery group. Active recovery group has positive effects on FEV $\mathrm{V}_{1}$ Both FVC and FEV1 measurements achieved positive results in terms of active recovery. Passive recovery stops suddenly muscular mobility after a high intensity exercise and leads to impaired rhythmic breathing during intense exercise. It is thought that this condition has a negative effect on the respiratory volume and therefore results in lower respiratory return than active recovery.

There was no reduction in cortisol hormone levels in the 5-min active and passive recovery after WanT, an anaerobic exercise test. It is seen that there is no effect of active and passive recovery in a short time and it supports the result that the increases next minutes of recovery after the exercise in the literature, and thus it is thought that cortisol can play an active role in the renewal of energy resources by maintaining the role of gluconeogenesis in recovery. The $\mathrm{PO}_{2}$ effect was found to be better in the passive recovery group than in the active recovery group. In the literature, it has been found that passive recovery is a more effective method in terms of $\mathrm{PO}_{2}$. After anaerobic exercise, ATP-PC deposits can be renewed by 5 minutes recovery. However, it was found that the 5 -minute recovery period was not sufficient for LA to return to the resting level. It has been found that neither the active nor the passive recovery has a different effect from each other during the 5-minute recovery period. Many studies similar to the results we have found in the literature, as well as their different conclusions, show that it is not clear which is a more effective method. We think that the cause of this is due to the different application of the factors such as the structure of the test applied, the type of blood intake, the severity applied in recovery, and the duration of recovery. Before the WanT test, when started AT recovery FVC and FEV1 values in respiratory function test, which we applied AT and RP5M, were found to be lower in passive recovery group than in active recovery group. It has been understood that active recovery group has positive effects on $\mathrm{FEV}_{1}$. It is thought that active recovery affects vital capacity positively. It has been seen that RP5M breathing values return to their resting values, and the exercise-induced $\mathrm{O}_{2}$ deficit will be closed in less than 5 minutes. In the future, studies to investigate pulmonary function values in the recovery phases after anaerobic test and to investigate whether or not they are effective in regenerating energy sources in cortisol recovery with gluconeogenesis will contribute to the results of our study and will clarify the unknowns in this area.

\section{Acknowledgements}

This research was supported by the scientific research projects unit of Inonu University with the project number 2016-144.

\section{Declaration of Conflicting Interests}

The author(s) declared no potential conflicts of interest with respect to the research, authorship, and/or publication of this article.

\section{References}

Ackerman, U. (2006). Physiology: PhysiologyIstanbul: Medical Publishing House.

Albayrak, X, Çiftçi, Y., Şen., Z., \& Demir, W. (2013). The acute effect of adrenocorticotropic hormone, cortisol level and leucocyte formula on training amateur footballers. International Hakam Academic Sports Right and Medicine J., 3, 24- 27.

Alemdaroğlu, U., \& Koz, M. (2011). Recovery after exercise; types and methods of recovery. Turkey Clinic of Sports Sciences, 3(1), 39-43.

Arslan, E., Hazır, T., Şahin, Z., Hazır, S., Karakoç, B., \& Aşçı, A. (2006). Effect of passive and active recovery at various intensities on blood lactate removal rate after supramaximal leg exercise in young soccer players. Hacettepe J. of Sport Sciences, 17(3), 112-123.

Atabek, H. Ç. (2015). Examination of some respiratory functions and biomotor features of 15-17 age group students who practice in different sports branches. İnönü University Physical Education and Sports J, 1, 2-3. 
Atan, T., Akyol, P., \& Çebi, M. (2013). Comparison of the respiratory functions of the athletes in the category of stars engaged in individual sports. Dicle Medical Journal, 40(2), 193-197. https://doi.org/10.5798/diclemedj.0921.2013.02.0253

Bompa, T. O., Keskin, İ., Tuner, B., Küçükgöz, H., \& Bağırgan, T. (2011). The theory and method of training: the period. Sports Publishing House and Bookstore.

Bosak, A., Bishop, P., Smith, J., Green, M., Richardson, M., \& Iosia, M. (2006). Impact of cold water immersion on 5 $\mathrm{km}$ racing performance. Journal of Sports Science Medicine, 38.

Çakmakçı, O., Aslan, F., \& Çakmakçı, E. (2010). The Effect of 12-Week Training Practice on Acid-Base Balance in Elite Boxers. Turk J Sports Med, 45, 92-103.

Çakmakçı, O., Fişekçioğlu, İ. B., Çınar, V., Akkuş, H., \& Kılıç, M. (2005). Comparison of some respiratory parameters of Turkey and Georgia-A- National boxing team. Spormeter Body Training and Sports J., 4, 134.

Çakmakc1, S. (2013). Effects of anaerobic exercise on some hormone levels in sporadic athletes in different branches (Published master's thesis). Selçuk University / Institute of Health Sciences, Konya.

Demiriz, M., Erdemir, İ., \& Kayhan, R. F. (2015). Effects of anaerobic interval training, aerobic capacity, anaerobic threshold and blood parameters at different resting intervals. International Journal of Sport, Exercise \& Training Sciences, 1(1), 1-8. https://doi.org/10.18826/useeabd.233120

Dupont, G., \& Berthoin, S. (2004). Time spent at a high percentage of max for short intermittent runs: active versus passive recovery. Canadian Journal of Applied Physiology, 29, 3-16. https://doi.org/10.1139/h2004-054

Ersöz, G., Koz, M., \& Çelen, Ş. (1996). One-time moderate acute exacerbation plasma cortisol level response in elite athletes. Physical Education and Sport Sciences Journal, 1(2), 31-33.

Fashi, M., Kazemi, A., Shahin, S. H., Khani, M., \& Rostamzad, K. (2014). The response of blood buffering capacity to three types of recovery during repeated high-intensity endurance training. Asian J. Med. Pharm. Res., 4, 36- 38.

Gelir, E., Koz, M. \& Ersöz G. (2013). Physiology Course Book. Ankara: Nobel Academic Publishing. Koçoğlu H. Tissue Oxygenation. Turk J Intense Care 2006, 4, 7.

Günay, M., Cicioğlu, İ., \& Kara, E. (2006). Exercise metabolic and heat adaptation. Ankara: Gazi Publication.

Gürses, V. V., Karabıyık, H., Akgül, M. Ş., Dölek, B. E., \& Koz, M. (2016). The effect of hydrotherapy on recovery in swimming. International Journal of Science Culture and Sport, 4(2), 607-614. https://doi.org/10.14486/IntJSCS583

Harbili, E., İnal, A. N., Gökbel, H., Harbili, S., \& Akkuş, H. (2007). Effects of active resting on blood lactate elimination after intense exercise. General Medical Journal, 17, 192-194.

Hazar, S., Hazar, M., Korkmaz, Ş., \& Bayil, S. (2011). The effect of graded maximal aerobic exercise on some metabolic hormones, muscle damage and some metabolic end products in sportsmen. Scientific Research and Essays, 6 (6), 1337-1343.

Hazır, T., \& Gül, Ş. (2016). The effect of passive and active recovery combined with passive, core exercises after high-intensity exercise on canine lactic acid elimination. Journal of Sports Sciences, 26(4), 165-176.

Hoffman-Goetz, L., \& Pedersen, B. K. (1994). Exercise and the immune system: a model of the stress response? Immunology Today, 15(8), 382-387. https://doi.org/10.1016/0167-5699(94)90177-5

Karakuşoğlu, Ö. (2008). Effect of anaerobic exercise on plasma atrial natriuretic peptide level in healthy men (Published Graduate thesis). Trakya University / Institute of Health Sciences, Edirne.

Kaya, M. (1994). Effect of Massage on Recovery after Exercise (Published doctorate thesis). Gazi University / Institute of Health Sciences, Ankara.

Koyama, Y., Koike, A., Yajima, T., Kano, H., Marumo, F., \& Hiroe, M. (2001). Effects of 'cool-down'during exercise recovery on cardiopulmonary systems in patients with coronary artery disease. Japanese Circulation Journal, 64(3), 191-196. https://doi.org/10.1253/jcj.64.191

Noyan, A. (1996). Physiology Course Book. Ankara: Meteksan Publication.

Özmerdivenli, R., \& Karacabey, K. (2000). Effect of exercise types on serum cortisol and DHEA-S hormones. Gazi $B E S B D, 2,11-14$.

Pınar, L. (2015). Basic Information on Neural and Muscle Physiology. Ankara: Academician Publication.

Sarı, R., Demirkan, E., \& Kaya, M. (2016). Examination of the effect of different restorations on lactic acid level in 
swimming. Journal of Contemporary Medicine, 6(4), 327-333.

Sevim, Y. (2010). Training Information. Ankara: Pelin Offset Tipo Printing Industry and Trade Ltd. Company.

Stöggl, T., Torres-Peralta, R., Cetin, E., \& Nagasaki, M. (2014). Repeated high intensity bouts with long recovery: are bicarbonate or carbohydrate supplements an option? The Scientific World Journal, 2-7. https://doi.org/10.1155/2014/145747

Temoçin, S., Ek, R. O., \& Tekin, T. A. (2004). The effect of speed and durability on the respiratory capacity of footballers. Sportmeter Body Training. and Sports J, 2(1), 31-35.

Wahl, P., Mathes, S., Köhler, K., Achtzehn, S., Bloch, W., \& Mester, J. (2013). Effects of active vs. passive recovery during Wingate-based training on the acute hormonal, metabolic and psychological response. Growth Hormone \& IGF Research, 23(6), 201-208. https://doi.org/10.1016/j.ghir.2013.07.004

\section{Copyrights}

Copyright for this article is retained by the author(s), with first publication rights granted to the journal.

This is an open-access article distributed under the terms and conditions of the Creative Commons Attribution license which permits unrestricted use, distribution, and reproduction in any medium, provided the original work is properly cited. 